\title{
Geomagnetism and Aeronomy activities in Italy during IGY, 1957/58
}

\author{
Antonio Meloni and Lucilla Alfonsi \\ Istituto Nazionale di Geofisica e Vulcanologia, Roma, Italy
}

\begin{abstract}
In 2007 several events were organized to celebrate the fiftieth anniversary of the International Geophysical Year (IGY, 1957-1958). The celebrations will last until 2009 and are taking place within different contexts: the International Polar Year (IPY), the International Heliophysical Year (IHY), the electronic Geophysical Year (eGY) and the International Year of Planet Earth (IYPE).

IGY offered a very appropriate and timely occasion to undertake a series of coordinated observations of various geophysical phenomena all over the globe. Italy took part in the broad international effort stimulated by IGY. In fact, Italy participated in observations and studies in many of the proposed scientific areas, in particular Geomagnetism and Aeronomy. The Istituto Nazionale di Geofisica (ING) started the installation of observatories, and updated and ensured continuous recording of geophysical observations. Geomagnetism, ionospheric physics, seismology, and other geophysical disciplines, were advanced. Although much of the work was undertaken in Italy, some attention was also devoted to other areas of the world, in particular Antarctica, where Italy participated in seismological observations. This paper gives a summary of the Geomagnetism and Ionospheric Physics activities within IGY. Furthermore, we highlight the importance of this historical event and its outcomes for the improvement of geophysical observations and the post-IGY growth of scientific investigations in Italy.
\end{abstract}

Key words IGY - Geomagnetism - Aeronomy History of Geophisics - Italy

\section{The Background}

In the 1950s a small group of eminent physicists including James Van Allen, Lloyd Viel Berkner, Siegfried Frederick Singer and Sidney Chapman, realized that the peaceful post war time was a good occasion to start a strong, internationally coordinated, scientific program for a new global geophysical endeavour. The time was right also due to the availabil-

Mailing address: Dr. Antonio Meloni, Istituto Nazionale di Geofisica e Vulcanologia, Via di Vigna Murata 605, 00153 Roma, Italy; e-mail: meloni@ingv.it; lucilla.alfonsi@ingv.it ity of new technologies: rockets, radar and numerous other geophysical techniques which had been developed during the war. Later on several other scientists from all over the world agreed to start this enterprise and, supported by the experience of the previous two International Polar Years, IPYs, in 1882/83 and in $1932 / 33$, agreed that the time was right for a new coordinated scientific effort (Buedeler, 1957; Gerson, 1958). Although the second IPY had occurred less than 50 years earlier, a reprisal after 25 years was motivated by the anticipated sunspot maximum of the 11-yr solar cycle in 1957-1958. The benefit was particularly strong for Geomagnetism and Aeronomy disciplines because variations of Earth's magnetic field and upper atmosphere are driven by sunspot related activity. The International Council of Scientific Unions (ICSU) endorsed the proposal and broadened its scope to incor- 
(a)

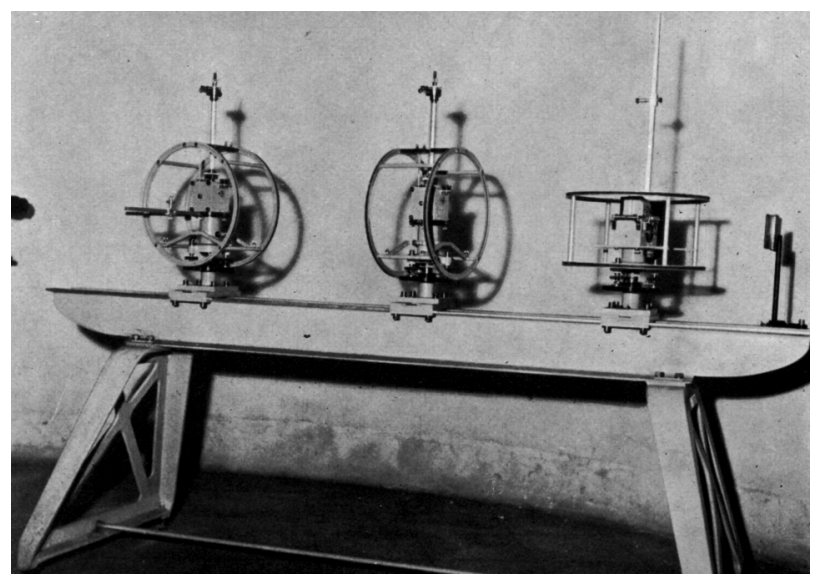

(b)

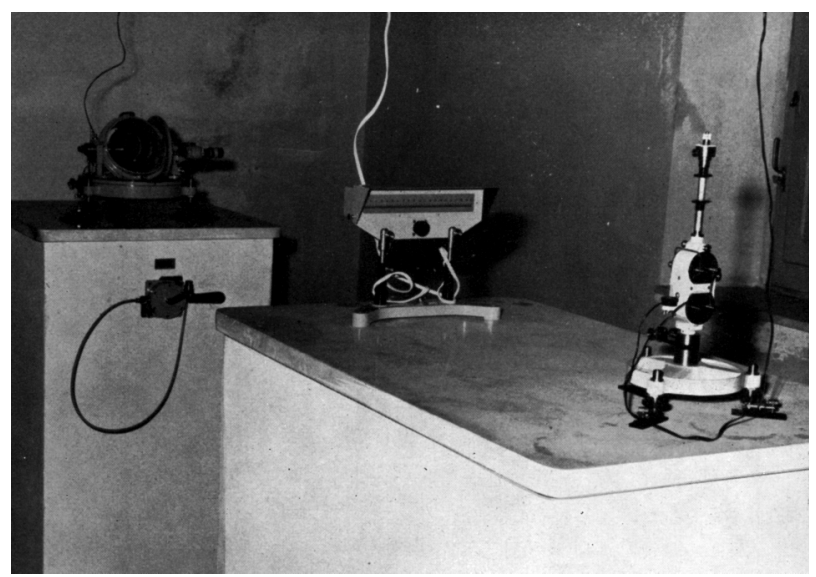

(C)

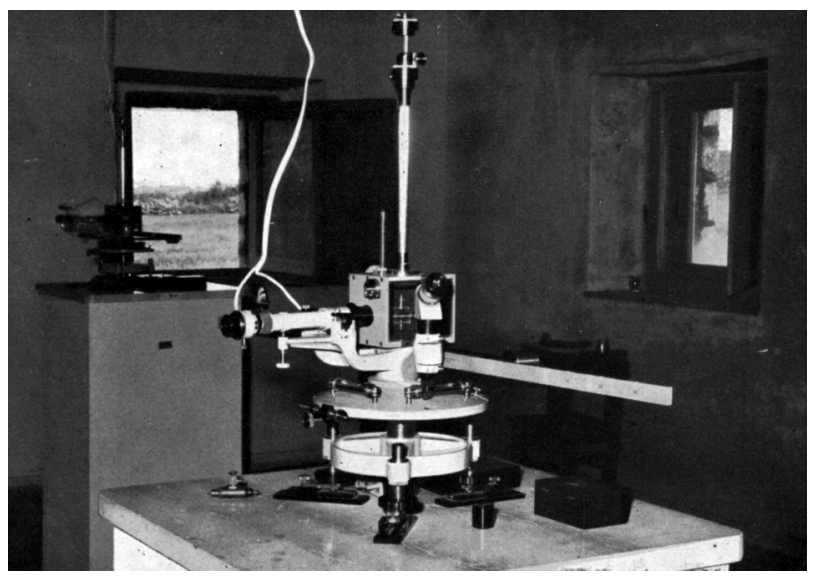

Fig. 1a-c. From the top: a) Ruska Magnetic Variograph ensamble, b) Ruska Earth inductor and c) Ruska Magnetic Theodolite, all at L'Aquila (1958) (from: Istituto Nazionale di Geofisica, 1963). 
porate studies of the whole Planet, rather than just in the polar areas, and called this enterprise the International Geophysical Year, IGY, to take place in 1957/58 (Giorgi, 1961). A special committee (Comité Spécial de l'Année Géophysique Internationale, CSAGI) was established as the governing body for all IGY activities; this committee would remain non-nationalistic and apolitical. S. Chapman was president and L.V. Berkner vice-president.

Twenty-six proposing Countries were involved in the proposal to ICSU; the Soviet Union and its allies were not initially included. It is pleasing to us to note that the city of Rome played a role in funding the IGY. In fact, participation of Soviet scientists in the Rome IUGG (International Union of Geodesy and Geophysics) Assembly in 1954 gave a good opportunity for a first open discussion on the IGY program. The Soviet Union delegates participated in the discussion with representatives of all other countries and subsequently the Soviet Union and its allies joined the program with a very comprehensive scientific approach. It was then a truly international effort, occurring against a background of cold war, suspicion and weapons escalation. The launch of the first artificial satellite, «Sputnik 1», on October 4, 1957, by the Soviet Union, and the launching of Explorer-1 by the USA on January 31, 1958, introduced a revolutionary geophysical investigation tool and signaled a more peaceful way for superpowers to compete.

The First Polar Year of 1882/1983 was truly interdisciplinary: auroral, magnetic and meteorological observations, but also botany, ethnology, geology and zoology were considered. The Second Polar Year (1932/1933) took advantage of the first telecommunication revolution but was unfortunately affected by the worldwide economic depression; it too achieved important results. New scientific fields and instruments were developed: in particular radiosondes (meteorological balloons with instruments and radio transmitters), improved magnetic instruments, ionospheric sounders and cameras for aurora photographs.

Storage and publication of results were impacted by the occurrence of World War II. By the time of the IGY new technological ad- vances, such as the birth of rocket science, and also a richer and more determined scientific audience, were favourable conditions for the beginning of a new quest.

In all, scientists from 67 nations organized a variety of activities in 14 working groups, each with its technical and scientific objectives, working in different experimental settings. The working groups were named: I) World days, and rapid communications, II) Meteorology, III) Geomagnetism, IV) Polar auroras and night sky, V) Ionosphere, VI) Solar activity, VII) Cosmic rays, VIII) Longitude and latitude determination, IX) Glaciology, X) Oceanography, XI) Rocketry and satellites, XII) Seismology, XIII) Gravimetry and XIV) Nuclear radiation. In addition, only for the USA, a technical panel was officially set up to attempt the launch of an artificial satellite into orbit around the Earth.

The IGY, began on July 1, 1957 and was completed on December 31, 1958, although a one year extension - the International Geophysical Cooperation - was granted. A comprehensive series of global geophysical activities allowed scientists from around the world to take part in a series of coordinated observations of various geophysical phenomena. During these two and one-half years, more than 10,000 scientists participated, making the IGY a unique event in the history of science and surely the greatest international geophysical scientific enterprise conducted up to that point. Much work was carried out in all geographical areas, but special attention was given to the polar regions, in the Arctic and Antarctic; here research on ice depths yielded radical new estimates of the earth's total ice content. IGY Antarctic research also contributed to improved meteorological forecasts, which were particularly weak in the southern hemisphere. Advances in cosmic ray research, climatology, glaciology, oceanography, terrestrial atmosphere, seismology, geomagnetism, theoretical analysis of glaciers, and many other fields of investigation were only some of the successful results of this extraordinary event.

\section{The Italian Participation in the IGY}

Following the invitation by ICSU, the Ital- 
ian National Research Council (CNR) founded the Italian National Committee for the IGY in 1957, called in Italian CNIAGI (Commissione Nazionale per l'Anno Geofisico Internazionale), as the national reference for IGY. The managerial and scientific activities were supported by a few Ministries, the Armed Forces and in general by the State administration. The Air Force in particular, furnished logistic support for the activities of various groups and was involved in gathering both meteorological as well as other types of data. The Navy placed three ships at the Commission's disposal for oceanographic research and the Ministry of Telecommunications organized rapid communication services for the «World days» working group.

Members of CNIAGI included physicists, geophysicists, astrophysicists and directors of the principal scientific institutions dealing with geophysics. CNR organized a special meeting with the delegates of the Ministries more strictly interested in the IGY activities (e.g. Public Education, Defence, Telecommunications and others) to determine the breadth and level of Italy's participation and to establish a financial plan for its implementation. During the meeting the delegates asked for extraordinary funds from the Ministries, and at the same time pushed CNR in promoting Italy's role in IGY by asking for extraordinary funds from the Italian Government. The proposal for extraordinary funds submitted by CNR, on the basis of the guidelines provided by the National Committee, was approved in August 1957. The Italian Government provided about 300 million Italian Lira (the initial request was for 900 million), at that time roughly equivalent to 500 thousand US Dollars. Meanwhile, as the proposal was being evaluated, CNR allocated 120 million Italian Lira from its ordinary budget (about 200 thousand US Dollars) to IGY activities. All these efforts granted Italy a major role in IGY: during the V Assembly of the Special Committee for the IGY, held in Moscow in 1958, the Italian delegates reported on their contribution to 12 of the 14 IGY working groups. After the success of the IGY, ICSU invited all the Nations involved to continue the international cooperation until the end of 1959.
The prosecution of the Italian activities was supported with further extraordinary funds provided by the Government in November 1959 (100 million Italian Lira) which was supplemented by a contribution from CNR of 25 million Lira (Giorgi, 1961). Italy did not participate in all 14 research groups of IGY. Participation in the observation of artificial satellites, for example, was considered secondary at the time and no participation was planned.

The general IGY program concentrated geophysical observation in 6 geographical regions. These regions were: a) three latitudinal bands spanning from pole to pole along three meridional sectors, centred at $10^{\circ} \mathrm{E}, 140^{\circ} \mathrm{W}$ and $75^{\circ} \mathrm{W}$; b) both polar regions and c) one equatorial region. Italy's activities were concentrated in the $10^{\circ} \mathrm{E}$ meridional zone.

The leading role of CNR during and just after the IGY granted a strong Italian contribution to IGY. Such a contribution is quantified as follows: 90 stations and observatories of 29 different Institutions operating within 12 of the 14 IGY working groups, with an overall rough estimate of about one thousand people involved, among them scientists, technicians and collaborators. The Italian Navy and Air Force also contributed significantly.

Among the participating Italian institutions was the former ING (Istituto Nazionale di Geofisica), now INGV (Istituto Nazionale di Geofisica e Vulcanologia). ING was particularly active during IGY and an intense development followed this important international activity (Calcara, 2004). In the following section, we report on the contribution of ING in the fields of geomagnetism, ionospheric physics and, to a lesser degree, seismology, covering in this way the three most important scientific activities carried out in IGY and in the Institute.

\section{Principal IGY Activities in Italy}

\subsection{Geomagnetism}

Before the IGY, there were only two geomagnetic field observatories in Italy: 1) the old Austrian-Hungarian observatory of Pola (Pula 


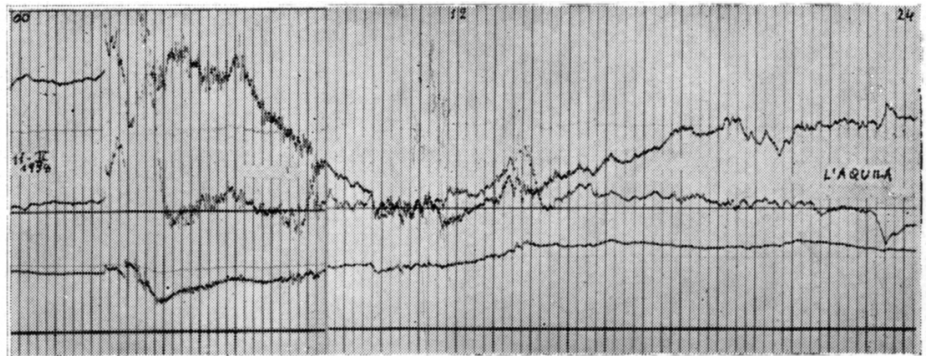

Fig. 2. Magnetic storm recorded on 11 February, 1958 at L'Aquila reporting the three traces of horizontal component, declination and vertical component time variations (from: Istituto Nazionale di Geofisica, 1963).

now in Croatia), operating from 1896 until 1920, when it was closed because of increased environmental electromagnetic noise, and 2) the Castellaccio observatory (Genoa) managed by the Naval Hydrographical Institute, equipped with instruments moved from Pola. Castellaccio began operations in 1932. The equipment for the absolute measurements and variometers at the Castellaccio observatory consisted of:

1) A Bamberg magnetic theodolite to determine every week the Declination (D) and the horizontal intensity $(\mathrm{H})$ of the geomagnetic field.

2) A Wild inclinometer for the regular determination of the magnetic Inclination (I).

3) Three Schultz variographs to record on photographic paper the three elements D, Z, H time variations.

4) A Kew magnetometer, i.e. a classic old magnetic theodolite, to determine $\mathrm{H}$ and $\mathrm{D}$ absolute values during field measurements.

In the 1950s, due to the vicinity of Castellaccio to the large city of Genoa, significant perturbations of anthropogenic origin affected the geomagnetic field measurements. For this reason, taking into account the recommendations included in the international program for IGY prepared by CSAGI, every possible effort was made to set up a new fundamental Magnetic observatory in Italy (Report on the Italian Programme for the International Geophysical Cooperation 1959, 1960).

Finding a proper location to perform absolute measurements, to record time variations and micropulsations of the geomagnetic field, was a difficult task. Starting in 1939, the ING, under the leadership of Antonino Lo Surdo, had already begun to investigate the best location for a national magnetic observatory. In particular, Maurizio Giorgi, at that time employed at ING, carried out several site survey campaigns all over Italy. After about two years of accurate measurements of the variations he identified a location, close to L'Aquila, which fulfilled the requirements of homogeneity and geological origin, and also lack of disturbances caused by industrialization and electric power lines. The location, near Masseria Calore in the Preturo area, $10 \mathrm{~km}$ away from L'Aquila $\left(42^{\circ} 23^{\prime} \mathrm{N}\right.$, $13^{\circ} 19^{\prime} \mathrm{E}$ ), was officially chosen to host the national magnetic observatory by the Italian Commission for the IGY. The leadership of all observatory operations was given to Franco Molina of ING, the leading scientist in Geomagnetism at ING until his retirement in 1984. Figure 1 shows the magnetic instrumentation installed in L'Aquila, fig. 2 shows the magnetometer traces for the strong magnetic storm of February 11,1958 , as recorded at L'Aquila on a photographic paper magnetogram.

During 1958, while the national magnetic observatory was being completed, the Italian Navy (Istituto Idrografico della Marina) installed a temporary experimental magnetic observatory in La Maddalena Island (Sardinia) (Giorgi, 1960a). This temporary observatory was equipped with:

1) A three component Askania magnetic variograph for the continuous photographic registration of the geomagnetic field.

2) A magnetometer GSI (Sokkisha) to measure the absolute elements (D, H, I, F and $\mathrm{Z}$ ) in campaigns as well as in the observatory. 
3) Two torsion Askania magnetometers to determine the relative variations of the $\mathrm{Z}$ component. ment.

4) An apparatus for calibration of the equip-

All magnetic bulletins produced by the Maddalena Observatory during the IGY were collected and published in a special booklet (Raccolta Bollettini Geomagnetici, 1960).

After a test phase in 1958, the observatory of L'Aquila started its operations officially in 1959. Variographic recordings of the geomagnetic field $(\mathrm{H}, \mathrm{D}, \mathrm{Z})$ by means of variographs of Ruska type started. From January 1959 absolute measurements were made with a Ruska theodolite and a Ruska earth-inductor. IGY installations for geomagnetism in most cases have become permanent, for example L'Aquila, and results of magnetic observations were published regularly afterwards as yearbooks and monthly bulletins.

Other temporary locations in Italy were chosen as sites for magnetic observations for the IGY; the recording of magnetic variations were performed in Anacapri, on Capri island (Naval Institute of the University of Naples) and at Laureto di Fasano operated by Bari University (Institute of Geodetics and Geophysics of the University of Bari). Micropulsation were recorded at the observatory of Monte Capellino close to Genoa (Giorgi, 1958).

\subsection{Ionosphere}

The start of IGY found an improved situation regarding ionospheric measurements in Italy. Vertical soundings of the ionosphere were initiated at the observatory located in S. Alessio (Rome) in 1948. Systematic observations began in 1956: the soundings were made every 30 minutes, or with higher frequency sampling during disturbed periods, sweeping a frequency range from 0.6 to $25 \mathrm{MHz}$. The echoes backscattered by the ionospheric plasma were visualized in a frequency versus time-delay diagram, known as ionogram, which at that time was printed on photographic paper; fig. 3 shows a view of the antennas used for the vertical ionospheric sounding in S. Alessio. The

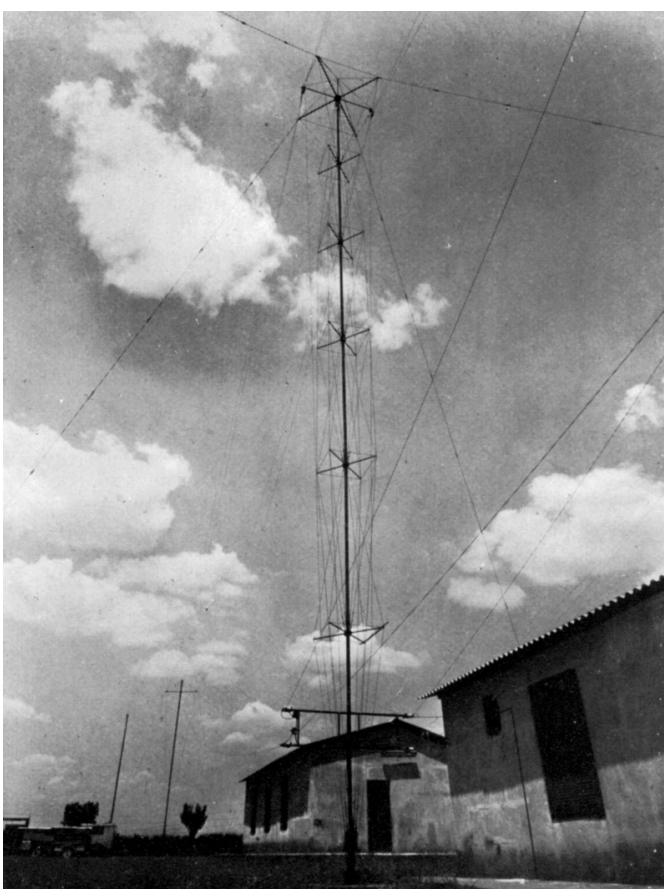

Fig. 3. A view of the antennas and huts for ionospheric vertical soundings in S. Alessio observatory (Rome, 1958) (from: Istituto Nazionale di Geofisica, 1963).

parameters derived by scaling the ionograms (an example is shown in fig. 4) were published in the ionospheric bulletin, where hourly values of the following quantities were reported: plasma frequencies of the $E, F 1$ and $F 2$ layers, i.e. $f_{o E}, f_{o F} 1, f_{o} F 2$; virtual heights of the same layers and of the sporadic $E$ layer, i.e. h'E, fEs, h'Es, h'F1, h'F2; M3000F2, the so-called maximum usable frequency (MUF) factor pertaining to oblique transmission over a $3000 \mathrm{~km}$ path with a single reflection from the $F 2$ layer. As a first overview of ionospheric conditions the measurements were also reported in daily diagrams, known as F-plots (fig. 5).

Another radio technique, oblique sounding, used to monitor the ionosphere along oblique paths, started in S. Alessio during the IGY and continued after the IGY period. The most significant ionosphere data, acquired for example during geomagnetic storms, were sent to the National Bureau of Standards for short-term 


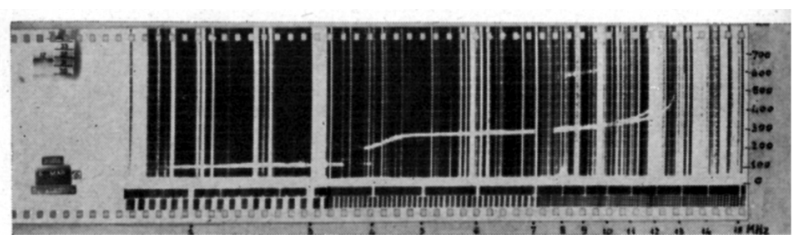

Fig. 4. Typical ionogram from S. Alessio observatory (Rome, 1958) (from: Istituto Nazionale di Geofisica, 1963).

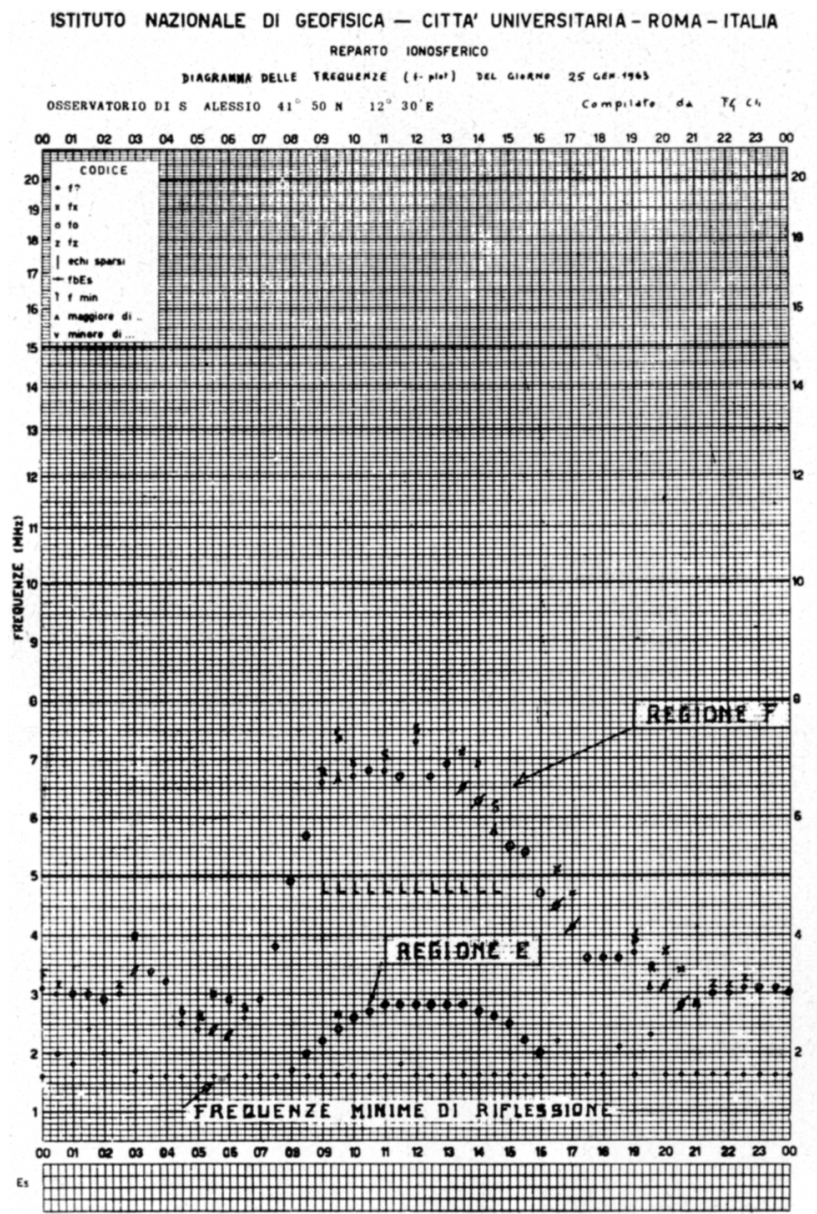

Fig. 5. Daily diagrams of the critical frequencies recorded on January, 251963 (from: Istituto Nazionale di Geofisica, 1963).

ionospheric forecasting on a global scale (ING, 1963).

Two other observatories at Nola (Naples), managed by the Centre for Radiopropagational and Radionavigational Studies of Naples, and at Monte Capellino (Genoa), managed by Istituto Geofisico e Geodetico of the University of Genoa, performed vertical ionospheric sound- 
ing. The latter also ran ionospheric absorption and radiopropagation experiments (Mariani, 1959).

Since August 1957 the «G. Marconi» Radioelectrical Centre performed regular backscattering experiments at fixed frequencies of 18.6 $\mathrm{MHz}$ and $22.3 \mathrm{MHz}$ with a rotating antenna under the supervision of Ivo Ranzi (University of Florence) and Pietro Dominici (ING). The equipment was located at Torrechiaruccia, Santa Marinella (Rome) (Giorgi, 1960b). It consisted of: a Main Generator, which provided short negative pulses at a rate of $25 \mathrm{sec}^{-1}$ to the Pulse Generator, able to transform them into rectangular pulses of 1000 microsecond duration; a Distance-Axis Generator; a Distance-Marks Generator; a transmitter consisting of a radio frequency Oscillator; a Power Amplifier; an Antenna Coupler, a four-element rotating Yagi Antenna (1 revolution per minute); and a Receiver consisting of a super heterodyne. In connection with this equipment, an analogical «Panorama» ionosonde, realized in 1954 in Germany by K. Bibl, was also used to follow large-scale dynamical phenomena, such as Travelling Ionospheric Disturbances and ionospheric storms. According to Dominici (1998), this type of ionosonde was the most advanced of the analogic ionosondes available at that time. In some locations, such as Rome, ionospheric monitoring instruments, have been updated and have undertaken observations continuously from the IGY to the present, with the results published regularly in monthly bulletins and yearbooks.

\subsection{Seismology}

One of the major activities undertaken today at INGV is Seismology. During the IGY, the Italian participation in seismological observations consisted primarily of microseism and long wavelength seismic observations. The observations were made by: the Vesuvian observatory (Naples), the Institute of Terrestrial Physics of the University of Naples, the Geophysical observatory in Trieste, and ING. ING, in particular, employed a long period pendulum (2 minutes) to measure the E-W component of ground motion at the Geophysical observatory of L'Aquila (Report on the Italian Programme for the International Geophysical Cooperation $1959 ; 1960)$. As part of a collaboration with the New Zealand Antarctic Program, Lieutenant Franco Faggioni, of the Italian Navy, participated as a seismologist to the activities of the seismological station at Scott Base; he was the only Italian scientist to participate in IGY activities in Antarctica. Lieutenant Faggioni was trained at ING for operations with seismic instruments (Fioretti et al., 2008).

\section{Final remarks}

With the exclusion of the observatories, stations and their measuring equipment, one of most important legacies left by IGY was the creation of the World Data Centre (WDC) system. Sustained and effective global observing systems can be effective only when, through collaboration, there are agreed data and information standards, and shared data and information infrastructure. The information infrastructure, requiring careful planning, governance and appropriate resourcing, was born during the IGY years. The Italian committee established an Italian Centre for the collection of all the data acquired during the IGY within the National Research Council (CNR), see Giorgi (1965). This Centre, in compliance with the International agreements and the aims of IGY, took part in the revision and forwarding of data to the WDCs. An agreement was reached with the Postal and Telecommunications Higher Institute to develop microfilms and photographic reproductions of magnetograms, tables, ionograms, etc.

As was the case for all the nations involved, the IGY ushered in a new era and a new way of doing science in Italy. Among the numerous legacies of IGY is the awareness that coordinated, continuous and systematic geophysical monitoring is a fundamental tool to understand the natural mechanisms ruling our planet.

The IGY legacy is demonstrated also by the considerable number of international scientific programs that were envisaged during IGY and that later were realized. Among the accom- 
plished scientific programs we mention: the World Magnetic Survey, that led to the publication of the World Magnetic Map in 1965, with Italy's participation; the Upper Mantle Program and, following, the International Geodynamics Program (IGP, 1970-1979). From IGP the «Progetto Finalizzato Geodinamica» of CNR was born in Italy. This program concentrated for the first time on the need for a scientific assessment of geological hazards, particularly earthquakes, volcanoes and tsunamis, and prepared the way for the reorganization of ING into INGV.

It is beyond the scope of this paper to give a complete and general scenario of the Italian activities during IGY. Our contribution has focussed on the observation and monitoring of the Earth's magnetic field and ionosphere, performed by scientists of the former ING, by highlighting the spirit of collaboration and the important heritage left by IGY, which still today influences the scientific activities at INGV.

The official IPY 2007-2008 is the fourth IPY. It marks the 50th anniversary of the IGY, and will be one of the most ambitious internationally coordinated scientific research programmes ever attempted. The observing period spans from 1 March 2007 to 1 March 2009 to include two full annual seasonal cycles in the Arctic and in the Antarctic. In this sense, then, the IGY is a still an ongoing endeavour (WMO, 2007).

\section{Acknowledgments}

The authors thank Dr G. Calcara for her assistance in finding ING historical documentation and Edward Cliver for his help in evaluating this paper. LA is supported by the research project RBAP04EF3A-007, funded by the Italian Ministry of Education.

\section{REFERENCES}

Buedeler, W. (1957): The International Geophysical Year, Unesco and its Programme XV, Unesco, pp. 72.

Calcara, G. (2004): Breve profilo dell'Istituto Nazionale di Geofisica (1936-1963), Quaderni di Geofisica, 36, 21.

Dominici, P. (1998): My first fifty years in ionospheric research, Annali di Geofisica, 41 (5/6), 857-883.

Fioretti, A., G. SAlvi and E. Mazzoli (2008): Gli anni polari pnternazionali: esplorazione e ricerca scientifica ai poli, (available on line http://www.annopolare.it/esplorazione/StoriaAnniPolari.pdf).

Gerson, N.C. (1958): From Polar Years to IGY, in Advances in Geophysics, edited by H.E. LANDSBERG and J. VAn Mieghem, vol. 5, (Academic Press Inc. Publisher, New York), pp. 52.

GioRGI, M. (1958): Geomagnetismo ed aurore polari, (Roma, CNR, Anno geofisico internazionale 1957-58), pp. 18.

Giorgi, M., (1960a): Sull'Osservatorio Magnetico Sperimentale dell'isola di La Maddalena, (Istituto Idrografico della Marina), pp. 7.

GioRgI, M. (1960b): La cooperazione geofisica internazionale dopo l'AGI, (CNR, Commissione Italiana per l'AGI), pp. 60.

GioRgi, M. (1961): L'anno geofisico internazionale e la partecipazione dell'Italia alla cooperazione geofisica mondiale, (CNR, Commissione Nazionale Italiana per la Cooperazione Geofisica Internazionale, Roma), pp. 67-80.

Giorgi M. (1965): CICIG, Catalogo dei dati geofisici raccolti durante l'AGI e la CGI, (CNR, Roma), pp. 70.

Istituto NAZIONALE DI Geofisica (ING) (1963): supplement of Annali di Geofisica, (Istituto Grafico Tiberino, Roma), pp. 114.

MARIANI, F. (1959): La ionosfera: radioconversazione tenuta alla RAI il 25 settembre 1957, (CNR, Anno geofisico internazionale 1957-58, ed. italiana), pp. 8.

Raccolta Bollettini geomagnetici (luglio 1958-dicembre 1960) (Istituto Idrografico della Marina Genova Marzo, 18 bullettins).

Report on the Italian Programme for the International Geophysical Cooperation 1959, (CNR, Commissione Italiana per l'anno geofisico internazionale, Roma, Italy), pp. 50.

World Meteorological Organization (WMO) (2007): The scope of science for the International Polar Year, 2007-2008, WMO/TD-No. 1364, pp. 79.

(received November 11, 2008; accepted January 10, 2009) 